\title{
Design and Construction of a Scroll Compressor of an Automobile Air Conditioning System
}

\author{
AKPOBI, JA; AJAYI, O I \\ Production Engineering Department, University of Benin, Benin City, Nigeria.
}

\begin{abstract}
This work focuses on the design and manufacture of a scroll compressor used in an automobile air conditioning system. A scroll compressor is a positive-displacement machine that compresses air with two interfitting spiral shaped scroll members. This compressor is of semi-hermetic design, and is

quiet, reliable and efficient in performance. @JASEM
\end{abstract}

The main function of a compressor is to admit fluid from a low-pressure region, compress it and deliver it to a high-pressure region (Rogers; Mayhew, 1994). Compressors are classified into displacement type and turbo type. The displacement types are further classified into reciprocating type and Rotary type (Creux, 1995). A Scroll compressor is a type of rotary type compressor. They are positive displacement machine that uses the compression action provided by two intermeshing spiral shaped scrolls, in which one is fixed and the other orbiting, (ASHRAE, 2004). Typical scroll compressors for automobile air conditioning system consists of the following components: Scrolls, Casing, shaft, bearing, refrigerant chamber, rubber seal, balancing spring, magnetic clutch and pressure valve, as shown in Figure 6.

Modern scroll compressor technology development only began in the 1970s where the concept of scroll compressor was re-invented by a refrigeration industry. Since their introduction into the air conditioning industry in the late 1980s, scroll compressors have been successful in a wide variety of both residential and commercial applications. In air conditioning, smaller compressors are found in residential and vehicle systems such as heat pump systems used to heat and cool individual homes or businesses. Larger compressors are found in commercial applications such as process chillers and in a variety of condensing unit systems. Refrigeration scroll compressors are applied in a wide range of applications including supermarket racks, bulk milk cooling truck transport and marine containers (American Refrigeration Institute, 1998; Carrier, 2004)

In this work, we present the design and manufacture of a Scroll Compressor of an automobile air conditioning system. To the best of our knowledge compressors are not currently produced within our country. Thus a lot of foreign exchange is being spent in importing them. Consequently, this research makes available the technology of scroll compressor design and manufacture; which will result in improvement of our economy and also advance our nation technologically.

Mode Of Operation And Compression Process: The design concept is based on the use of two intermeshing spiral scrolls to compress (as shown in Fig. 1) air by rotating the shaft through a drive unit from an electric motor. The flanks of the upper and lower scroll vanes form crescent shaped pockets. As the lower scroll orbits, the sealing points on the vane flanks moved inward pushing crescent shaped pockets toward the involute center. As the pockets move, they decrease in volume and consequently compress the trapped gas (McCulloughm, 1979; Wang; Chopey, 1994).

The first orbit begins with the ends of both scrolls fully open, allowing the interstitial space to fill with low-pressure refrigerant gas. The lower scroll's orbit eventually closes the first pocket of refrigerant gas. As the first orbit ends, the first pair of crescent shaped pockets has moved inward to a middle position and the scroll's outer ends begin opening again to admit more low pressure refrigerant gas. The second orbit pushes the first gas pocket toward the center of the scroll set, continually decreasing the gas volume and increasing the gas pressure. The third orbit begins with crescent shaped pocket just outside of the scroll center. As the third orbit continue, the inner ends of the vanes break contact admitting the compressed gas to the center discharge port. The third orbit continues the compressor cycle, discharge high-pressure refrigerant gas.

The design drawing of the Fixed Scroll and Orbiting Scroll are shown in Figs. 1-7. 


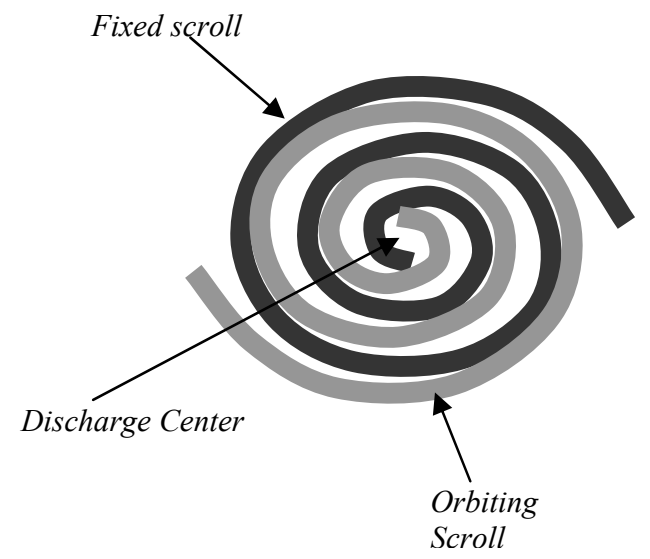

Fig. 1. Compression process
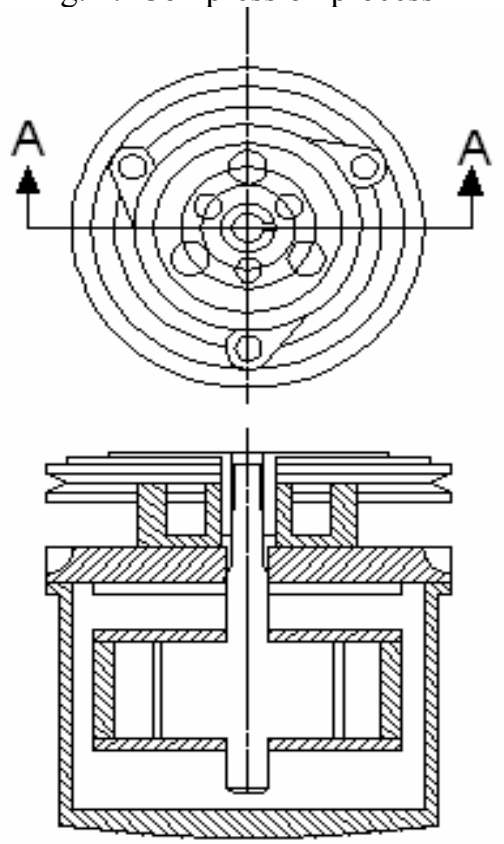

Fig. 2: Sectioned view of Scroll Compressor

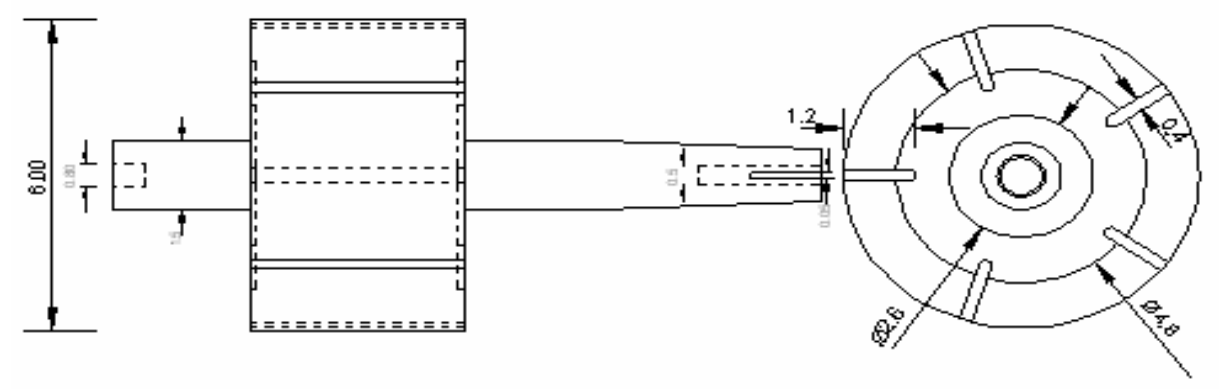

Fig. 3: Shaft 

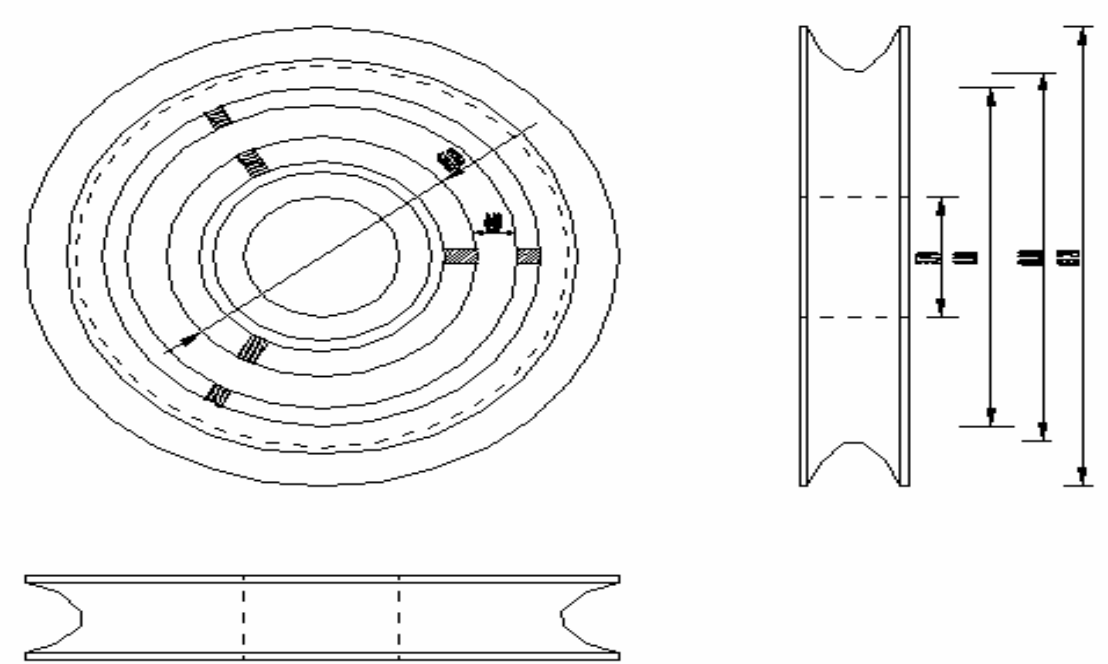

Fig. 4: Fixed Scroll
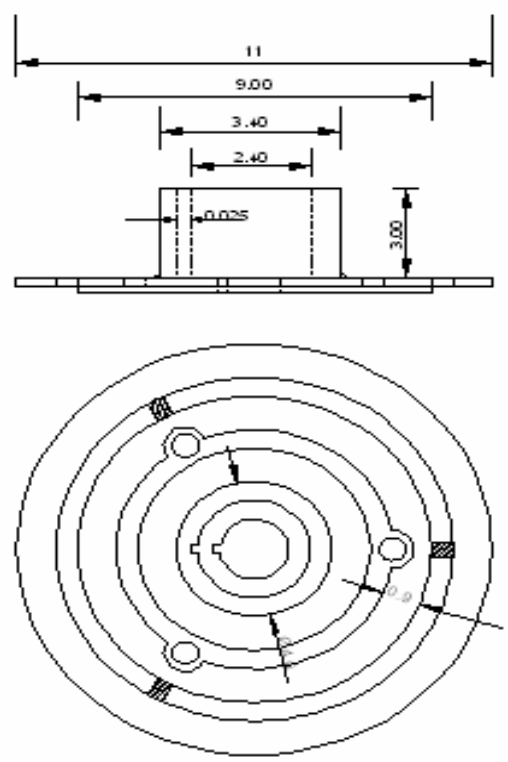

Fig. 5: Orbiting Scroll

Compressor Parameters: The shaft transmits the rotary motion to the orbital motion of the lower scroll. The shaft also carries the counter weight necessary to balance the compressor mechanisms.

The following are considered during shaft design: Torsional Moment $\left(M_{t}\right)$, shaft diameter $(d)$, shear $\operatorname{stress}(\tau)$, Twist angle $(\theta)$, Permissible load $\left(F_{\text {max }}\right)$, casing thickness $T_{c}$

Shaft design: The design of power transmitting shaft basically consists of the determination of the correct shaft diameter to ensure satisfactory strength and rigidity during operation under various loading and working conditions. Shafts are usually circular in cross sectional and may either be hollow or solid. Their design is well expounded in many standard texts (Shigley; Mischke, 2001; Hall, et. al. 2002; Khurmi and Gupta, 2005). The shaft transmits the rotary motion to the orbital motion of the lower scroll. The shaft also carries the counter weight necessary to balance the compressor mechanisms (Orthographic drawing shown in Fig. 3). In designing the compressor shaft we considered the design of the shaft with its vanes. For effective discharge of high pressure 5 vanes with an angle of $72^{\circ}$ where used. In the design for 


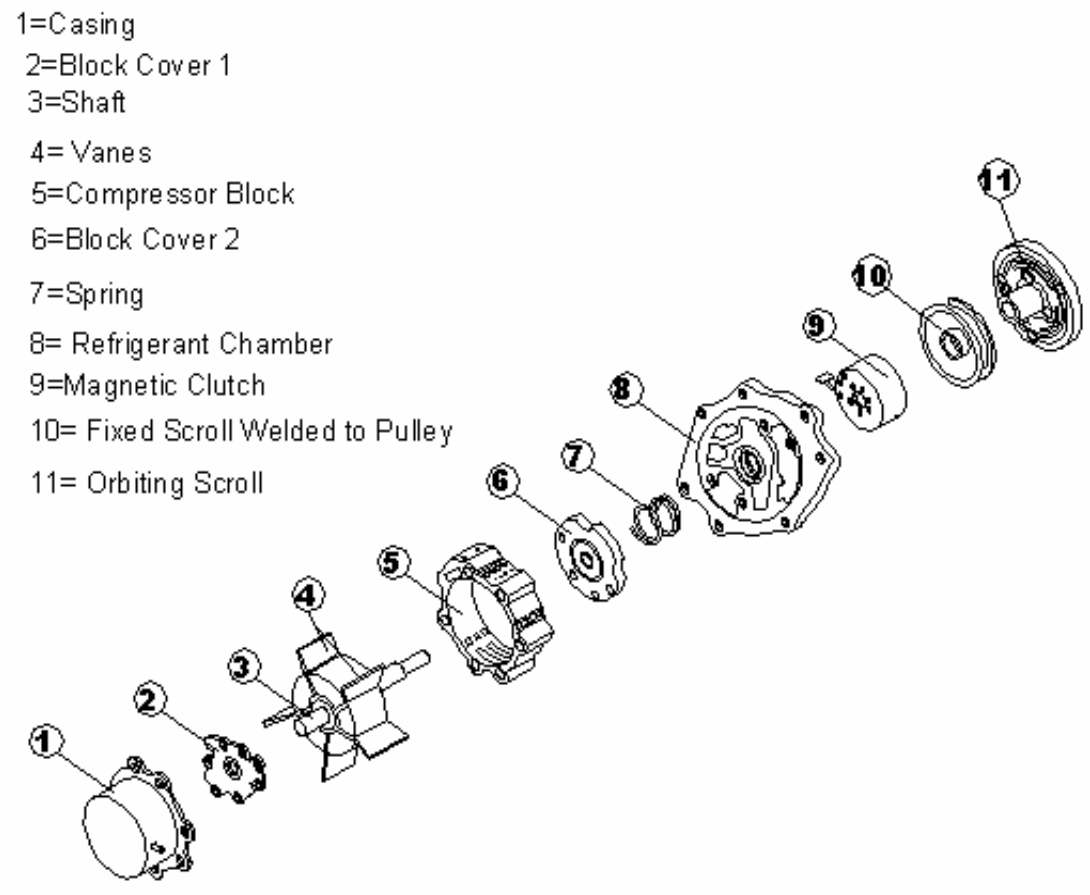

Fig. 6: Exploded View of Scroll Compressor

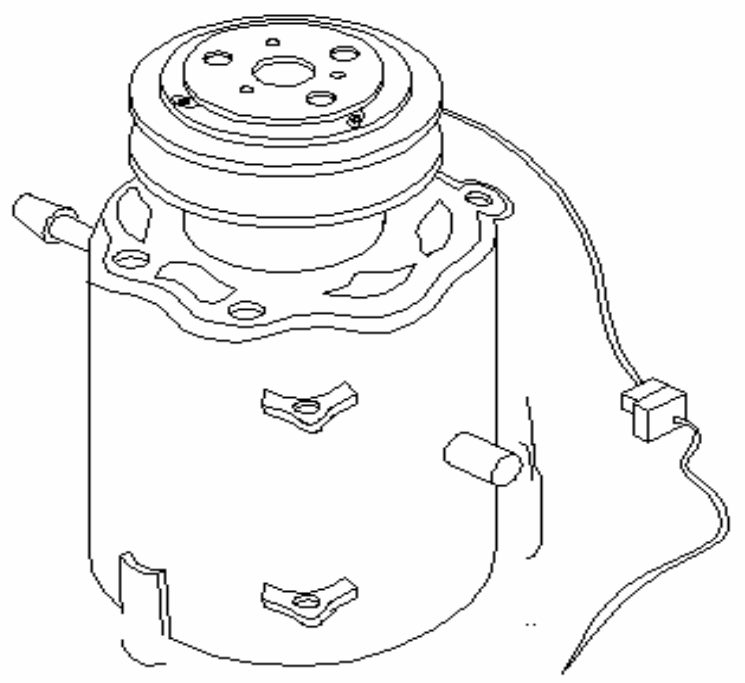

Fig. 7: Assembled Scroll Compressor

Torsional moment $M_{t}=\frac{9550 P_{m}}{N}$, and is evaluated as: $23.88 \mathrm{Nm}$

Shaft diameter $d^{3}=\frac{16}{\pi S_{s}} \sqrt{\left(k_{b} M_{b}\right)^{2}+\left(k_{t} M_{t}\right)^{2}}$ where:

$K_{b} \quad$ Fatigue factor applied to bending moment

$K_{t} \quad$ Fatigue factor applied to torsional moment

$M_{b} \quad$ Bending moment, $(\mathrm{Nm})$

$M_{t} \quad$ Torsional moment $(\mathrm{Nm})$

AKPOBI, JA; AJAYI, O I 
But the shaft has only torsional stress and therefore $K_{t}$ is unity'

$K_{t}=1$ and assuming $K_{b}=1.5$.

From the calculation of Bending Moment Diagram we have the maximum bending moment, permissible of shaft $=37.18 \mathrm{Nm}$

using the ASME code for solid shaft eqn. with $M_{t}=23.88 \mathrm{Nm}$ and $M_{b}=37.18 \mathrm{Nm}$

we have $d=0.01428 \mathrm{~m}$, or

$$
d=14.28 \mathrm{~mm}
$$

From the ASME standard size of shaft, we use shaft of diameter of $15 \mathrm{~mm}$

Therefore, $D=4 \times 15=60 \mathrm{~mm}$

$$
\text { 3. Shear stress }(\tau)=\frac{M_{t} R}{J} \text { and is evaluated as: } 1.40 \times 10^{5} \mathrm{~N} / \mathrm{m}^{2}
$$

Where $J=1.277 \times 10^{-6}$

4. Twist Angle $(\theta)=\frac{584 M t L}{G d 4}$ and is evaluated as: $0.44^{\circ}$

5. The maximum load (permissible load) for rigidity

$$
F_{\max }=\frac{3 \delta E I}{L^{3}}
$$

Where $I$ (moment of inertia) $=\frac{d^{4}}{64}$, and is evaluated as: $2.00 \times 10^{-9}$

$$
\begin{array}{r}
\delta=\frac{\rho L^{3}}{3 E I}, \text { and is evaluated as: } 1.40 \times 10^{-3} \\
F_{\max } \text { and is thus evaluated as: } 7.8 \mathrm{KN} .
\end{array}
$$

Amount of deflection $(y)=\frac{M_{b}}{E I}$, and is evaluated as: $9.30 \times 10^{-3} \mathrm{~mm}$

\begin{tabular}{ll} 
TABLE 1: & SHAFT SPECIFICATION \\
\hline PROPERTY & APPROX. \\
& VALUE \\
\hline Power transmitter from motor $(P)$ & $7.50 \mathrm{KW}$ \\
Rotational speed of motor $(N)$ & $3000 \mathrm{rev} / \mathrm{min}$ \\
Fatigue factor to bending moment $\left(K_{b}\right)$ & 1.50 \\
Fatigue factor to torsional moment $\left(K_{t}\right)$ & 1.00 \\
Weight of pulley $(W)$ & $165.00 \mathrm{~N}$ \\
Number of vanes & 5 \\
Angles $\left({ }^{\prime}\right)$ & $72^{\circ}$ \\
Tension in tight side $\left(N_{t}\right)$ & $356.00 \mathrm{~N}$ \\
Tension in loose belt $\left(N_{2}\right)$ & $160.00 \mathrm{~N}$ \\
Rotational speed of motor $\left(N_{m}\right)$ & $3000 \mathrm{rev} / \mathrm{min}$ \\
Power transmitted $(P)$ & $7.50 \mathrm{KW}$ \\
Mass of 1 mm of belt $(M)$ & $0.12 \mathrm{Kg}$ \\
Coefficient of friction $(f)$ & 0.30 \\
Diameter of shaft $(d)$ & $15.00 \mathrm{~mm}$ \\
Weight of shaft $\left(W_{S}\right)$ & $9.98 \mathrm{~N}$ \\
Shear stress of shaft $\left(S_{S}\right)$ & $1.4 \times 10^{5} \mathrm{~N} / \mathrm{m}^{2}$ \\
Twist angle of shaft $(\theta)$ & $0.44^{0}$ \\
Lateral rigidity $\left(F_{\max }\right)$ & $7.80 \mathrm{KN}$ \\
Deflection on shaft $(y)$ & $9.3 \times 10^{-3} \mathrm{~mm}$ \\
\hline
\end{tabular}

Compressor casing design: Compressor Casings have the tendency to burst under the influence of internal pressures. This necessitates the design for the casing thickness, so as to be able to withstand the high internal pressure developed, during operation. The casing thickness $T_{c}$ is designed using equation 7 


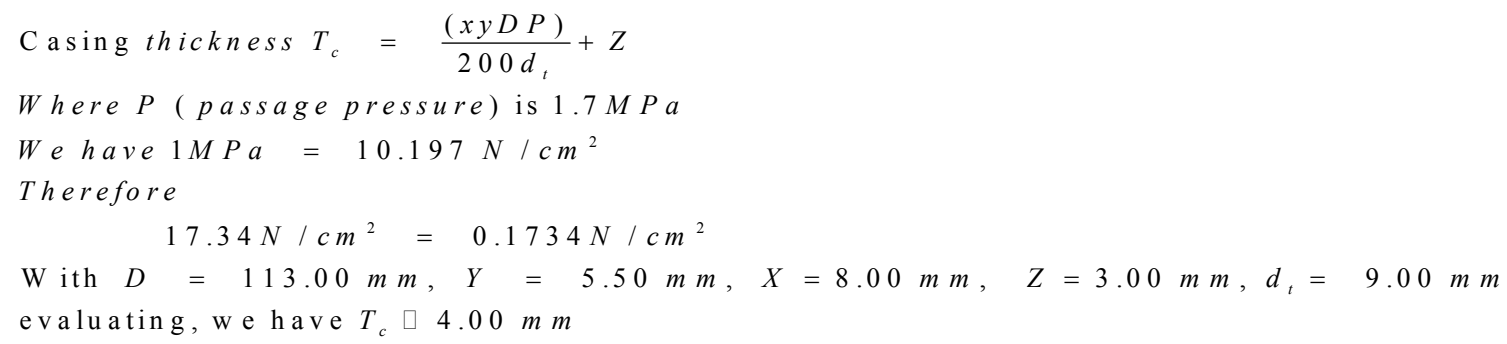

Leakage between chambers: Ideally, the two halves of a scroll compressor remain perfectly in contact as they rotate. In reality it is not practical to machine them accurately enough for this to be the case, and instead there is a narrow gap. The gap is around one micron across, this may be increased by wear and/or poor machining and it is known that if it reaches around eight microns, the compressor becomes useless.

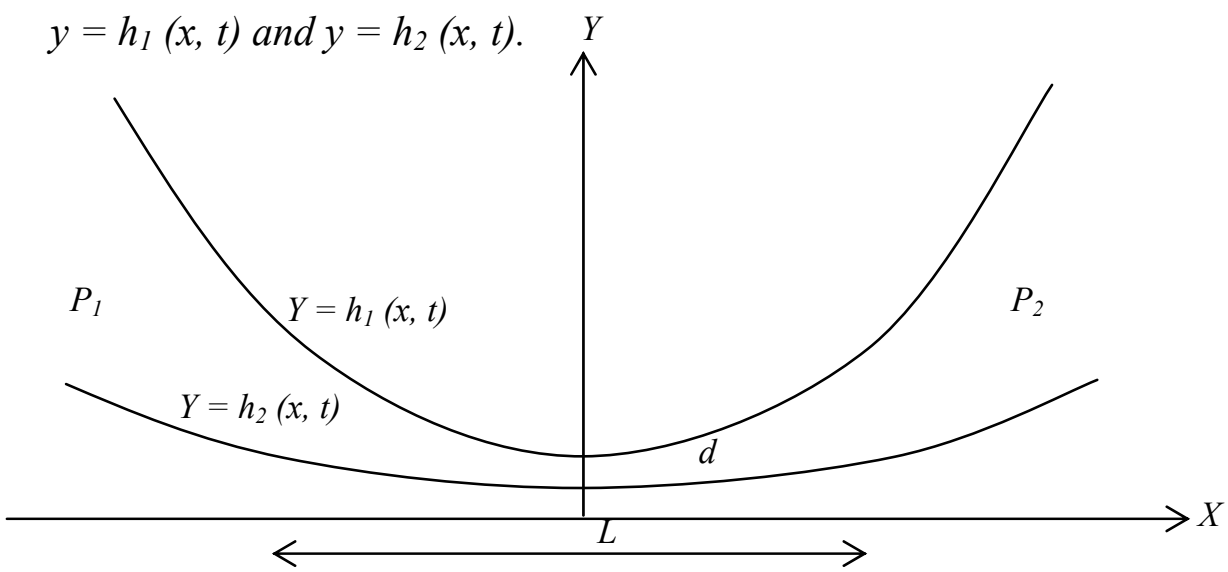

Fig. 8: leakage between chambers graph

That is why we have to analyze the flow through this gap so as to determine the leakage between neighboring chambers in the compressor. A schematic of the geometry is given in the Fig. 8 see also (Howell, 2001). A gap of typical thickness $d$ and length $\mathrm{L}$ separates two adjacent chambers containing gas at pressure $\mathrm{P}_{1}$ and $\mathrm{P}_{2}$. The length scale $\mathrm{L}$ appears

$$
\begin{aligned}
& \rho_{t}+\operatorname{div}(\rho u)=0 \\
& \frac{d u}{d t}=-\operatorname{grad} p+(\lambda+\mu) \operatorname{grad} \operatorname{div} u+\mu \nabla^{2} u
\end{aligned}
$$

to be somewhat arbitrary. A local coordinate system is adopted with $\mathrm{x}$ pointing along the gap and $\mathrm{y}$ pointing across it. With respect to these coordinates we denote the bottom and to top scroll walls (both of which are moving as the compressor rotates) by the governing equations for the flow are the compressible Navier - strokes equations
Where $\rho, u$ and $P$ are the density, velocity and pressure fields, $\lambda$ and $\mu$ are the dilatational and shear viscosities and $\mathrm{d} / \mathrm{dt}$ is the usual convective derivative. Equation (1) represents conservation of mass, and must be satisfied by any continuous with velocity $u$ and density $\rho$, while equation (9) is the generalization of the usual incompressible Navier-stokes equation, which is recovered if div $u$ is set to zero. Given the change in pressure $\Delta \mathrm{P}$ across the gap we can deduce a typical gas velocity $u$ by balancing the pressure gradient with viscous drag in Equation (2) (Okendon, 1995)

$$
U=\frac{d^{2} \Delta P}{\mu L}
$$

And for dimensionless parameter is the ratio between this and the velocity due to rotation of the compressor.

$$
\Omega=\frac{\omega L}{u}=\frac{\mu \omega L^{2}}{d^{2} \Delta P}
$$


we can immediately deduce a typical rate of leakage from the velocity scale $u$, the rate which gas is lost through is of order $U_{\mathrm{d}}$, an so the cumulative loss over a cycle is typically $u_{d} / w$ (Wylen, et. al. 1994). We simply have to compare this with the original area of

$$
\text { Relative loss }=\frac{d^{3} \Delta P}{\mu \omega L^{3}} \quad 12
$$
a chamber to obtain the relative loss of gas to leakage.

Table 2: Estimated parameter for leakage between chambers

\begin{tabular}{lc}
\hline Property & Approx. Value \\
Viscosity $(\mu)$ & $10^{-5} \mathrm{Kg} / \mathrm{m}$ \\
Gap thickness $(d)$ & $10^{-6} \mathrm{~m}$ \\
Contact length $(L)$ & $10^{-2} \mathrm{~m}$ \\
Rotation frequency $(W)$ & $47.33 \mathrm{~s}^{-1}$ \\
Pressure change $(\Delta P)$ & $1.60 \times 10^{6} \mathrm{~Pa}$ \\
\hline
\end{tabular}

Estimated parameter values for leakage between chambers in the scroll compressor as shown in Table 2 above shows that relative loss is rather small about $0.3 \%$, however, it is clearly, highly sensitive to increase in $\mathrm{d}$.

Force at discharge port $=$ pressure $x$ area of discharge part

Area of disch $\arg e \frac{\pi d^{2}}{4}=\frac{\pi 9^{2}}{4}=63.62 \mathrm{~mm}^{2}$

the computed force is $11.03 \mathrm{~N}$

Deter min ation of output temperature $T_{2}=T_{1}\left(\frac{P_{2}}{P_{1}}\right)^{(k-1) / k}$

$T_{1}=27^{\circ} \mathrm{C}=300 \mathrm{~K}, \mathrm{P}_{1}=1.70 \times 10^{5}, \mathrm{P}_{2}=1.01325 \times 10^{5}$ and $\mathrm{k}=1.4$

from which we have $\mathrm{T}_{2}=347.8 \mathrm{~K}$ or $\square 75^{\circ}$

Determination of Power of Compressor: The design of the Power of Compressor, is well treated in standard texts (Rogers and Mayhew, 1994). The power of a compressor is given by

Power of compressor $=\frac{K w R T 1}{k-1}\left(\frac{P_{2}}{P_{1}}\right)^{(k-1) / k-1}$

Where $R=$ gas cons $\tan t$ given as $c_{p}-c_{v}=0.287$

$\omega=47.33 \mathrm{rad} / \mathrm{s}, P_{2}=1.7 \times 10^{5} \mathrm{~N} / \mathrm{m}^{2}, P_{1}=1.01325 \times 10^{5} \mathrm{~N} / \mathrm{m}^{2}$ and $k=1.4$

on evaluating, we have power of compressor as $2.27 \mathrm{KW}$

Power of compressor $\approx 3 \mathrm{hp}$ 
Manufacturing Process: The major parts of the scroll compressor are the scrolls, casing, shaft and refrigerant chamber. Other parts of the scroll compressor are rubber seal, balancing spring; bearing, magnetic clutch and pressure valves were brought out items. So we have before us three major parts to be constructed: the scrolls, casing and shaft while the refrigerant chamber was cast due to its intricate shape. (Sectioned view shown in Fig. 2)

The Scrolls: To construct these Scrolls a freestanding strip of metal was machined into the form of an involute curve and bound on one edge by a solid flat base. They were machined from carbon steel. The Scrolls have one stationary element and while the other rotates in an orbiting motion around the rotor center. These two elements (identical spirals as shown in Figs. 1 and 9) that are assembled at $180^{\circ}$ phase difference. An anti rotation device, in this case an Oldham coupling, was used to ensure that these identical spirals were are assembled at $180^{\circ}$ phase difference. Oldham coupling held the lower scroll at a fixed angular position preventing rotation and allowing radial movement in an orbital path. The magnitude of the orbital motion is dependent on the base circle radius and the wall thickness.

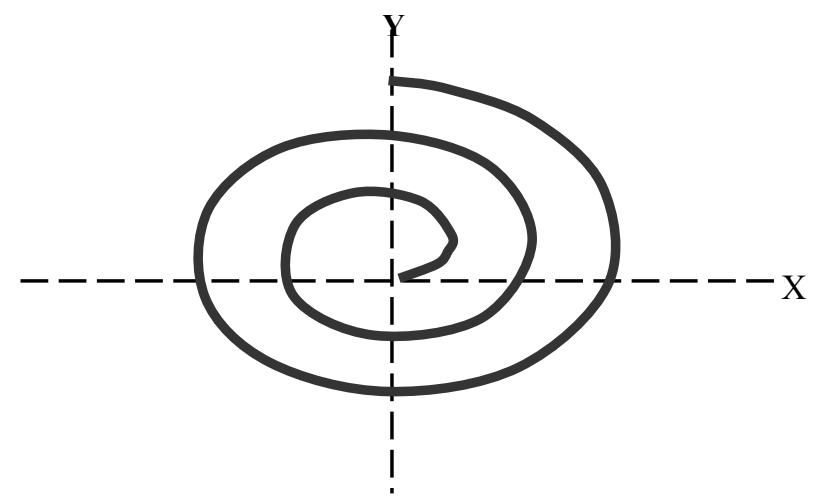

Fig. 9: A simple spiral

Manufacture of Casing: The compressor casing was fabricated using mild steel plates to thickness of $4 \mathrm{~mm}$. From economic viewpoint we choose to fabricate using machining processes on the lathe and then welded the parts together. The scroll compressor casing is a cylindrical vessel oriented vertically and divided into a low pressure and a highpressure end. The largest volume of the casing operates at the refrigerant suction pressure.

A relating small high-pressure areas lies above the compressor's stationary scroll and acts as a discharge muffler to reduce gas pulsation sound and vibration. Cool refrigerant suction gas enters large suction shell/casing via the lower connection. Gas velocity drops substantially in the casing allowing lubricant and any small amounts of liquid refrigerant top separate from the gas. In the scroll compressor, all of the suction gas passes upward through the rotor on its way to the scroll set. The small amount of oil carried to the compressor as a mist entrained in the refrigerant gas provides the necessary lubrication for sealing the scroll vanes. Compressed gas discharges through a check valve into the high-pressure dome and then exits the compressor shell through a discharge connection. The lower portion of the shell serves as an oil and liquid reservoir. The compressor high capacity sump enables operation in systems with long runs and large refrigerant charges.

Testing of Compressor: After assembling (shown in Fig. 7) of the scroll compressor, the next was to test if the machine is working appropriately. On the completion of the test the following observation and result were achieved:

. A suction pressure imparted to it by the compressor was acting upon the air coming in the compressor.

The amount of air at the outlet is directly roportional to that at the inlet

- The main purpose of the compressor (i.e. increase the pressure and temperature of refrigerant gas) was achieved.

Several tests were carried out on the scroll compressor and the results are tabulated below.

Initial Pressure $=1.01 \times 10^{5} \mathrm{~N} / \mathrm{m}^{2}$ (atmospheric pressure)

Initial Temperature $=27{ }^{\circ} \mathrm{C}$ 
Table 3: Result of Test

\begin{tabular}{cccc}
\hline S/N & $\begin{array}{c}\text { PRESSURE OUT } \\
\left(\mathrm{N} / \mathrm{m}^{2}\right)\end{array}$ & $\begin{array}{c}\text { TEMPERATURE } \\
\text { OUT }\left({ }^{\mathrm{O}} \mathrm{C}\right)\end{array}$ & $\begin{array}{c}\text { EFFICIENCY } \\
\%\end{array}$ \\
Test 1 & $1.42 \times 10^{5}$ & 57.60 & 63.73 \\
Test 2 & $1.37 \times 10^{5}$ & 54.20 & 56.67 \\
Test 3 & $1.65 \times 10^{5}$ & 71.80 & 93.33 \\
Test 4 & $1.62 \times 10^{5}$ & 70.20 & 90.00 \\
Test 5 & $1.59 \times 10^{5}$ & 68.10 & 85.63 \\
\hline
\end{tabular}

Then the corresponding average efficiency is $77.88 \%$

Discussion: The design concept is based on the use of two interfitting spiral scroll to compress air by rotating the shaft with the help of pulley via a belt drive from electric motor. The size of the machine was put under strict consideration. Scroll compressors of an air conditioning system of vehicles used in the world today are of small sizes. The pressure of the refrigerant gas going into the compressor determines the magnitude of the pressure produced by the compressor at the outlet.

Conclusion: We have presented in this work the design and manufacture of a scroll compressor. The machine (scroll compressor) helps to compress the air that goes into the condenser of an air conditioning system of a vehicle, then to the receiver, to the expansion valve, and evaporator. The compressor operates with an efficiency of $77.88 \%$.

\section{REFERENCES}

American Refrigeration Institute. (1998). Standard 550/590, Water chilling packages using the vapour compression cycle. Air-conditioning and Refrigeration institute, Arlington, VA. http://www.ari.org/cert/document/ARI_OM_550 $\underline{590 . p d f}$

ASHRAE(2006).Handbook, Heating, Ventilating and Air - $\quad$ Conditioning systems http://www.lib.berkeley.edu/ENVI/HVAC.html

Brown, R N (2001). Compressor selecting and sizing. $2^{\text {nd }}$ edition, Gulf publishing company, Houston, Texas.

Carrier (2004). High Efficiency Compression, for Commercial and Industrial Application. Carrier. corporation. Syracuse, New York,

http://www.xpedio.carrier.com/idc/groups/piblic/doc uments.pdf
Chopey, N P(1994). Chemical Engineering Handbook. $2^{\text {nd }}$ Edition, McGraw-Hill, New York.

Creux, L. (1905) Rotary Engine Us Patient 801182.

Hall, A S; Holowenko, A R; and Laughlin, H G (2002). Shaum's outline series of theory and

problems of machine design, Metric edition. TataMcGraw- Hill, London.

Howell, P. (2001). Fluid mechanical modeling of the scroll compressor. University of Oxford,

Longman, Essex, UK.

Khurmi, R S. and Gupta, J K (2005). A Textbook of Machine Design, Metric Edition. Eurasia Publishing House Limited, New Delhi

McCulloughm, J E; Hirschfold, F. (1979). The scroll machine - an old principle, McGraw-Hill, New York

Ockendon, H.; and Ockendon, J R (1995).Viscous flow. Cambridge Inc. London

Rogers, G F C; and Mayhew, Y R (1994). Engineering Thermodynamics. $4^{\text {th }}$ edition E.LB.S., Addison-Wesley, London.

Shigley, J F; Mischke,.C R(2001). Mechanical Engineering Design, $6^{\text {th }}$ Edition. McGraw-Hill, New York.

Wang, S K (1998) "The Handbook of Air conditioning and refrigeration McGraw Hill, Inc.

New York.

Wylen, V.; Sountag, R E; and Borgnakke, C (1994). Fundamentals of classical Thermodynamics. Wiley., London. 